\title{
Analysis of the level of process maturity in the activities of Russian companies
}

\author{
Pavel Trifonov
}

Associate professor, PhD; Financial University under the Government of the Russian Federation

\begin{abstract}
The article analyzes the process maturity in Russian companies in a number of sectors of the economy based on a survey of experts from professional communities, and also assesses the level of implementation of BPM systems in the activities of Russian companies. On the basis of an expert survey, the factors that encourage the management of Russian companies to implement BPM systems were identified, as well as an assessment of the factors that hinder the decision to implement BPM systems in the companies ' activities. The expected effect of implementing BPM systems is determined based on the studied experience of experts in implementing systems, as well as the result of analyzing the preferences of company management when choosing an information management system. In most of the companies surveyed, process management is used for key processes that are regulated and strategic in nature. The results of the study allow us to draw conclusions that the needs of Russian companies ' management in using business process management systems are related to the need to ensure the company's sustainable development.

Keywords: BPMS, BPMN, business process, business process management system, process maturity, process management, business models, business digitalization.
\end{abstract}

\section{Introduction}

In recent years of the Russian economy functioning, leaders of many domestic enterprises have encountered a number of barriers of economic, social and technological origin. These restrictions arose in the face of economic sanctions and, as a result, the forced search for alternative markets for production distribution. As a result, there was a need to change the business models of the functioning of organizations in the view of the limited resource base and resources saving, increased competition in a number of sales markets and in the view of the search for investments for the transition to a new technological stage of development, due to the digitalization in all spheres of social and economic life.

The global BPM market (BPM - business process management) is growing at an average rate of $15 \%$ per year and is approaching to the amount of $\$ 8$ billion. For large global companies, the business process management has already become an integral part of their business. The Russian customer has only recently realized all the advantages of BPM and today is trying to determine clearly where such solutions are needed [2].

A new technological challenge for the digital economy for Russian business has become the need to move from an outdated instrumental system of organization management methods 
based on functional and resource approaches towards to a more adaptive one to market changes, client-centric and more sustainable management system, with the process approach as the methodological basis. According to international quality standards ISO 9000: 2000, the process approach is identified as one of the eight principles of quality management that contributes to the achievement of quality goals, and "the desired result is achieved more efficiently when the corresponding resources and activities are managed as a process" [1].

The transition to a new process management system management system involves a number of changes in the conceptual perception and development of business models and organization of business activities; together with the review of organizational relations, principles of coordination, control, communications, responsibility, development and management decision-making technologies; with shift of emphasis from bureaucratic organizational management structures towards adaptive matrix and design structures. An important sign of such changes is the transition to a new organization management information system, the object of which is a business process system that links production operations with market activity. Such an approach in the $21^{\text {st }}$ century was called the process management, which was based on the usage of the BPM systems technology (or BPMS).

\section{Methods}

The purpose of this study is to identify the causes and characteristic features of the process transformation of Russian enterprises broken down by each industry characteristics in comparison with the results of 2015. This study is based on an expert survey (data collection was carried out using Google Documents) and further statistical processing of the results in MS EXCEL. Most of the respondents surveyed are heads of structural units responsible for managing business processes in the largest Russian corporations of various industry sectors.

As part of the study, the tasks were set to identify correlations between such variables as the level of knowledge and competencies in the field of BPMS management tools for managers of the studied companies and the level of process maturity, which is expressed in the results of the implementation of the process approach in the enterprises. It is also necessary to conduct a comparative analysis of the level of process maturity between enterprises representing different industries ("energetics", "telecommunications", "manufacturing", "mining", "trade", "services", "real estate development").

The final stage of the expert survey will be the identification of factors, which affect the development of BPMS implementation technologies in Russia. It will be based on ranking the answers and determining the most significant factors (having about $80 \%$ weight in the structure of the total value of the indicator).

\section{Results}

It is important to note that interest in process management is growing and over the past 5 years the percentage of adherents to this approach has been at least $85 \%$, which is confirmed by the data from the above survey. A special feature of the occurrence of the process approach in the organization's management system is the description and regulation of its business processes. The domestic BPM market accumulates a growing number of active participants and inspires its supporters amongst the senior management of a number of domestic companies [3]. At the moment, Russian companies do not actively use the process approach methods, techniques and BPM standards, relying on their own decisions. Despite this circumstance, most managers take care of the implementation of the enterprise's business process management system. More than the half of respondents say that the description of key processes has been completed and a number of companies have completed totally the description of all business processes (12\%). This fact significantly distinguishes the current 
state of Russian companies from the situation, which was actual five years ago. In 2019, the number of companies that made the description of all their processes has increased in 4 times, compliments of the sectors "energy", "telecommunications" and "mining". By virtue of the pro-active approach of companies from the service industry, the number of organizations, which make documentation records of their key business processes increased by $6 \%$ (Fig. 1 ).

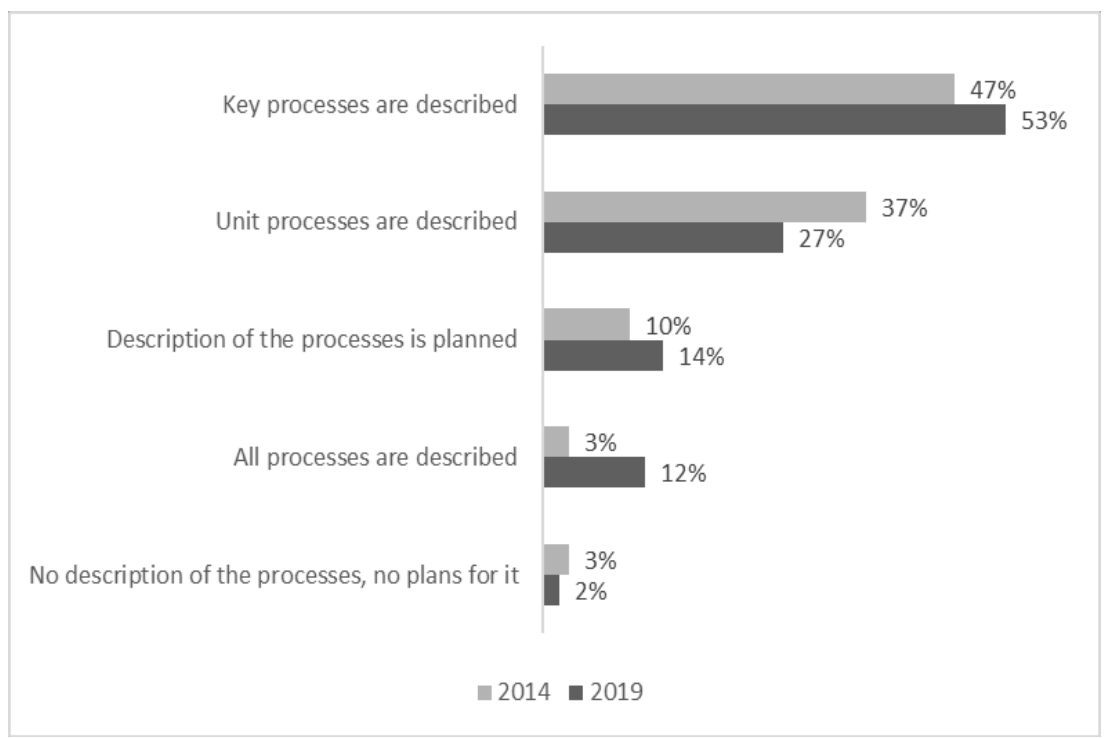

Fig. 1. Status of the description of processes in companies, compiled by the author.

About a quarter of the company executives surveyed $(22 \%)$ confirmed that there is ongoing monitoring and improvement of most processes in information systems. The increase in the number of companies from $3 \%$ to $22 \%$ representing the vanguard of process management in Russia indicates success in the development of process literacy projects and the distribution of package products of BPMS integrator companies. In addition, the development of the process approach is provided by market factors (competition and cost optimization), which determine the reasons for choosing a new business model. The success in the total optimization of the business process management system is the achievement of companies from the "mining" and "distribution and generation of energy" industries. However, for most companies, process control is applied only to the key processes, so the key business processes are regulated and they generally ensure the achievement of goals. In 2019 , the number of such representatives has already reached $70 \%$, against the situation five years ago, in 2014 - it was $58 \%$. Such statistics became possible due to active investments in the informatization of their companies in the sectors "energy", "telecommunications" and "mining" (Fig. 2). These companies are focused on the gradual improvement of key processes, large-scale automation of processes at the enterprise level, as well as on the determination of process efficiency indicators $[4,7]$. The percentage of organizations, that have not yet implemented process management does not decrease and fluctuates in the range of $23-27 \%$, but such organizations have an understanding of the need for this task. The reduction from $14 \%$ to $12 \%$ in the number of organizations for which the issue of implementing process management is not considered, is encouraging. Companies, which belongs to the "real estate development" and "trade" sectors, which have chosen a conservative path of development, are due to low production technologies and the specific nature of project activities. 


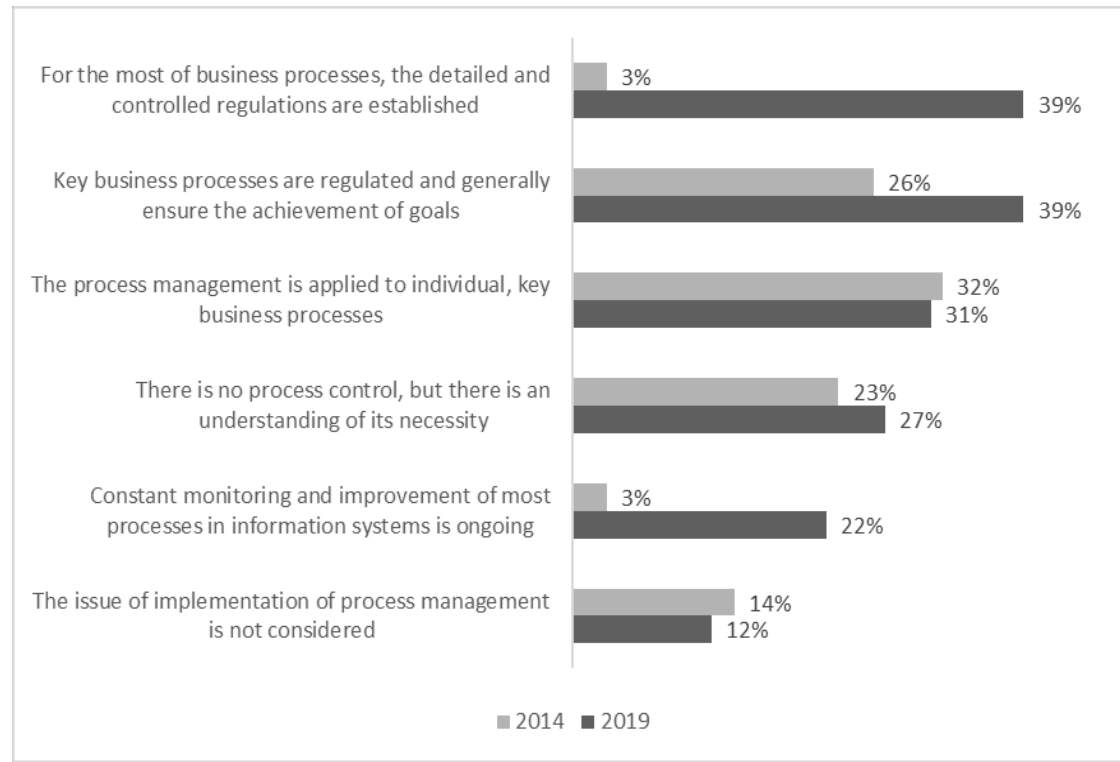

Fig. 2. Characteristics of the level of process maturity, compiled by the author.

In recent years, the demand for BPMS products has been growing, the information content of the effect of introducing BPM amongst most specialists causes a desire to develop further in this direction. First of all, this is due to the fact that most organizations have rather limited opportunities for saving and increasing work efficiency by combining accounting functions. The second reason could be defined as the transition of the business to digital processes, which, consequently, requires serious investments for its implementation. In this regard, the management of companies has two ways of development of events, this is either to hire an additional number of employees, or to implement BPM. At the moment, both in the domestic and foreign markets, there is serious competition for quality products, which encourages a number of companies to move from the control of particular indicators to the focus exclusively on the final result.

If one talks about stimulating factors for the implementation of BPMS, then the majority of surveyed managers noticed that the manageability and transparency of operational activities in the organization increased (about 70\%). Others emphasized increasing the operational efficiency of processes (the number of respondents increased from $59 \%$ to $67 \%$ ). For many respondents, the reduction in costs and increase in profits (about 55-57\%) (Fig. 3) was an important factor. The rest of them named more specific reasons for the choice: the need for type processes practices, reducing the time for launching new products on the market and increasing customer focus. The unanimous and solidary opinion, which grew for $8 \%$ over the past 5 years, in regard to the increase in operational efficiency after the introduction of BPMS, was expressed by representatives of the following sectors: "energy", "real estate development", "mining", "financial services". 


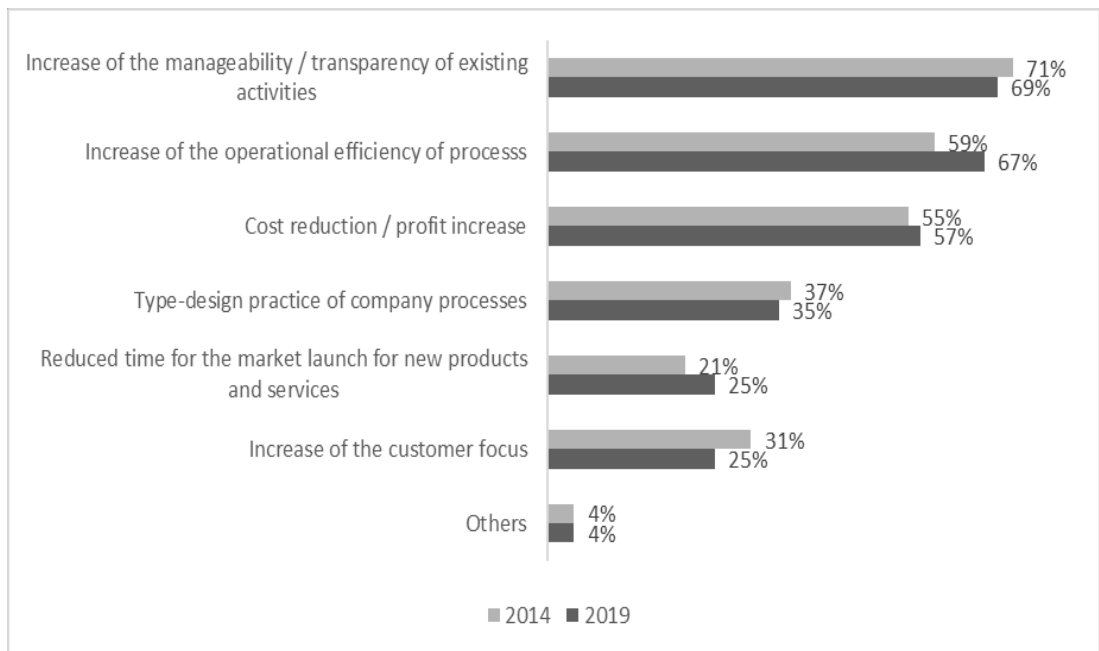

Fig. 3. Factors, that stimulate the development of business process management systems, compiled by the author.

Along with the factors promoting the development of BPMS, the article analyses the key barriers that impede the development of the process approach in the country. A significant proportion is accounted for by the human factor, expressed in an insufficient level of competence and inertia of employees $-41 \%$ and $31 \%$, respectively. This effect appears in bulk in the sectors of "real estate development" and "financial services", and is caused by problems in the personnel policy and in the labour market for these areas. But several factors can be attributed to the most problematic areas: the lack of interest in this topic among the top management of the company (increased up to $39 \%$ ), the low level of maturity of the company (increased up to $29 \%$ ) and the necessity to increase the personnel (29\%). The values of these factors have grown in recent years by more than 10 points and this suggests that there is personal responsibility for the crisis situation at a number of enterprises. Such "sad" facts are present in the sectors of "manufacturing" and "energy". Representatives of the "real estate development" and "mining" sectors named "lack of financial and time resources" as the reasons for refusal to introduce a process approach in their companies.

As a positive assessment of the development of the BPM market, one should mark a decrease by a noticeable $10 \%$ of the influence of such factors as "there is no understanding of the need to use BPMS in company management" and "insufficient evidence of the effect of the implementation of such systems" (Fig. 4). 


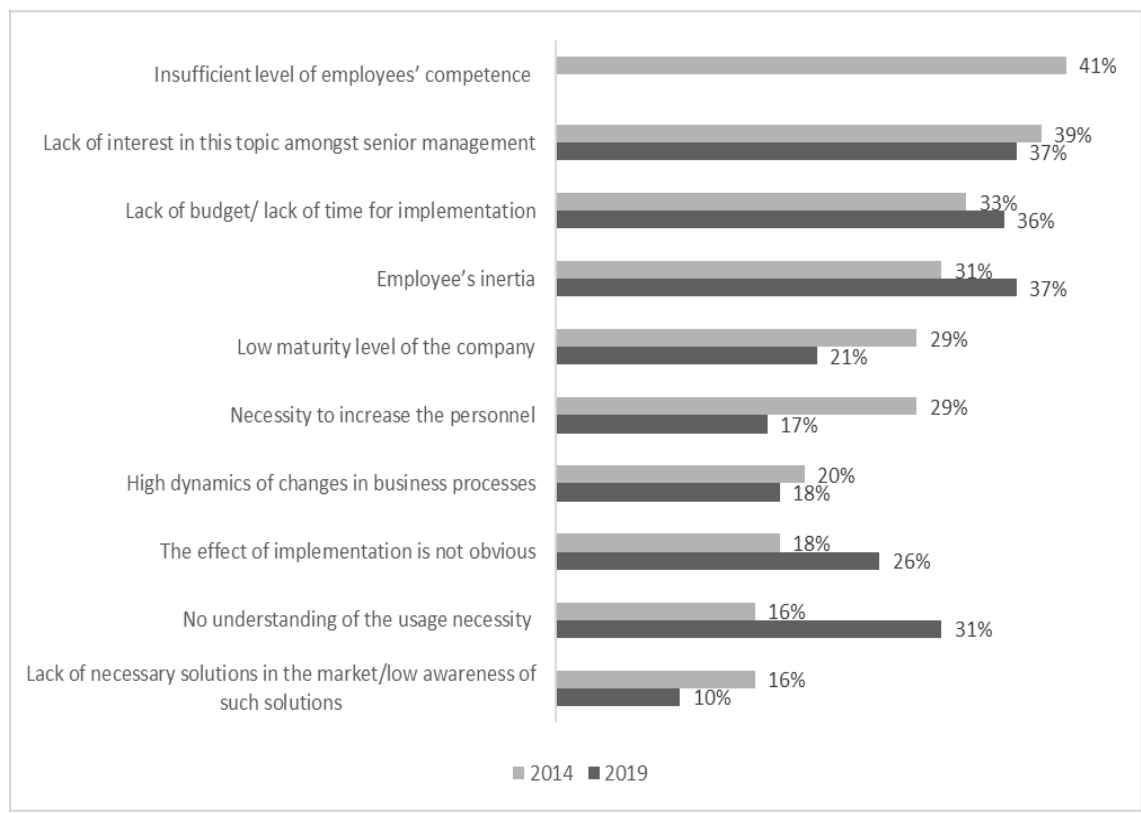

Fig. 4. Constraining factors for the implementation of BPMS in organizations, compiled by the author.

\section{Conclusions}

In recent times, environmental conditions have changed so quickly that companies have to adapt to them, and therefore either change the management structure or structural methods and techniques. BPMs allow one to automate business processes by designing them in user mode, as well as analyze the operational performance of designed processes. Such process management tools allow one to erase the boundaries between business and IT and offer users a convenient means of implementing processes through their visual description and configuration.

The main challenges in Russia for the implementation of the process approach and support systems remain behavioural and systemic market problems. As the recommendation for the development of systems, it should be considered the possibility of including in the platform of the national project "Digital Russia" the sections on improving literacy, accessibility and stimulating the process literacy amongst business representatives and in the educational system.

\section{References}

1. Quality Management Systems. Fundamentals and vocabulary. Interstate standard. GOST ISO 9000-2011. M.: Standartinform, 2012.

2. The Russian market of BPM systems in the context of the economic crisis. [Electronic resource]. Access Mode: https://www.itweek.ru/idea/article/detail.php?ID=171683. Date of access $(03 / 29 / 2019)$.

3. Koptelov A. How BPM is used in Russia [Electronic resource]. - Access mode: http://www.i-love-bpm.ru/files/event/forum2013/A1-Classic-BPM.pdf /Date of access: $(03 / 29 / 2019)$. 
4. The Russian BPM market in 2015-2016. " The study of the company "Logic BPM" and TAdviser [Electronic resource]. - Access mode: http://www.tadviser.ru/index.php//Date of access: 03/28/2019.

5. BPM market in Russia: on the way to business efficiency, S. Svinarev [Electronic resource].- Access mode: https://www.pcweek.ru/idea/article/detail.php?ID=170929/ Date of access: 03/29/2019.

6. The Russian market of BPM systems in the context of the economic crisis. [Electronic resource]. Access Mode: https://www.itweek.ru/idea/article/detail.php?ID=171683.

7. Koptelov A. How BPM is used in Russia [Electronic resource]. - Access mode: http://www.i-love-bpm.ru/files/event/forum2013/A1-Classic-BPM.pdf /

8. BPM market in Russia: on the way to business efficiency, S. Svinarev [Electronic resource].- Access mode: https://www.pcweek.ru/idea/article/detail.php?ID=170929/

9. Van der Aalst, W. M. P., ter Hofstede, A. H. M., \& Weske, M. (2003). Business Process Management: A Survey. Business Process Management, pp.1-12.

10. Mendling, J., Dustdar, S., Gal, A., García-Bañuelos, L., Governatori, G., Hull, R., ... Dumas, M. (2018). Blockchains for Business Process Management - Challenges and Opportunities. ACM Transactions on Management Information Systems, 9(1), pp. 1-16.

11. Schmiedel, T., vom Brocke, J., \& Recker, J. (2013). Which cultural values matter to business process management? Business Process Management Journal, 19(2), pp. 292317.

12. Schmiedel, T., vom Brocke, J., \& Recker, J. (2014). Development and validation of an instrument to measure organizational cultures' support of Business Process Management. Information \& Management, 51(1), 43-56.

13. Vom Brocke, J., Schmiedel, T., Recker, J., Trkman, P., Mertens, W., \& Viaene, S. (2014). Ten principles of good business process management. Business Process Management Journal, 20(4), pp. 530-548

14. Rosemann, M. and vom Brocke, J. (2010), "The six core elements of business process management", in vom Brocke, J. and Rosemann, M. (Eds), Handbook on Business Process

Management. Introduction, Methods and Information Systems, Springer, Berlin, pp. 109-124

15. Vom Brocke, J., Seidel, S. and Recker, J. (2012), Green Business Process Management: Towards the Sustainable Enterprise, Springer, Heidelberg

16. G.D. Bhatt, M.D. Troutt, Examining the relationship between business process improvement initiatives, information systems integration and customer focus: An empirical study, Business Process Management Journal, 11 (2005) pp.532-55

17. R.T. Wright, D.E. Campbell, J.B. Thatcher, N. Roberts, Operationalizing multidimensional constructs in structural equation modeling: Recommendations for IS research, communications of the Association for Information Systems, 30 (2012) 367412

18. W. Bandara, A. Alibabaei, M. Aghdasi, Means of achieving business process management success factors, in: 4th Mediterranean Conference on Information Systems (MCIS 2009), Athens, Greece, 2009.

19. ] D. Mani, A. Barua, A.B. Whinston, An empirical analysis of the impact of information capabilities design on business process outsourcing performance, MIS Quarterly, 34 (2010) pp39-62

20. R.P. Bagozzi, Measurement and meaning in information systems and organizational research: Methodological and philosophical foundations, MIS Quarterly, 35 (2011) 261292. 